\title{
Noninvasive Mechanical Ventilation in Acute Respiratory Failure Patients: A Respiratory Therapist Perspective
}

\author{
V. Hidalgo ${ }^{1}$, C. Giugliano-Jaramillo ${ }^{1}$, R. Pérez ${ }^{1}$, F. Cerpa ${ }^{1}$, H. Budini ${ }^{1}$, D. Cáceres ${ }^{1}$, \\ T. Gutiérrez ${ }^{1}$, J. Molina ${ }^{2}$, J. Keymer ${ }^{1}$ and C. Romero-Dapueto ${ }^{*}, 1$
}

\author{
${ }^{I}$ Servicio de Medicina Física y Rehabilitación, Clínica Alemana de Santiago, Santiago, Chile \\ ${ }^{2}$ Escuela de Kinesiología, Universidad del Desarrollo, Santiago, Chile
}

\begin{abstract}
Physiotherapist in Chile and Respiratory Therapist worldwide are the professionals who are experts in respiratory care, in mechanical ventilation (MV), pathophysiology and connection and disconnection criteria. They should be experts in every aspect of the acute respiratory failure and its management, they and are the ones who in medical units are able to resolve doubts about ventilation and the setting of the ventilator. Noninvasive mechanical ventilation should be the first-line of treatment in acute respiratory failure, and the standard of care in severe exacerbations of chronic obstructive pulmonary disease, acute cardiogenic pulmonary edema, and in immunosuppressed patients with high levels of evidence that support the work of physiotherapist. Exist other considerations where most of the time, physicians and other professionals in the critical units do not take into account when checking the patient ventilator synchrony, such as the appropriate patient selection, ventilator selection, mask selection, mode selection, and the selection of a trained team in NIMV. The physiotherapist needs to evaluate bedside; if patients are properly connected to the ventilator and in a synchronously manner. In Chile, since 2004, the physioterapist are included in the guidelines as a professional resource in the ICU organization, with the same skills and obligations as those described in the literature for respiratory therapists.
\end{abstract}

Keywords: Acute respiratory failure, noninvasive mechanical ventilation, physioterapist, respiratory therapist.

\section{INTRODUCTION}

In Chile, a physioterapist has several functions inside the ICU. Elsewhere in the world, inside an intensive care unit (ICU), there are respiratory therapists (RT), who have a fairly described role in literature. Several studies have described the competencies of an RT as a professional who is an expert in respiratory care, in all areas of mechanical ventilation (MV), pathophysiology and indication of ventilation, interpretation in laboratory tests, MV pharmacology, aerosol therapy, artificial airway management, weaning, and advanced techniques like prone position and ECMO [1]. Manage maneuvers of airway permeabilization, pathophysiological respiratory management concepts, application of different types of oxygen therapies, mechanical ventilation to improve gas exchange, and optimize the medical management of acute respiratory failure (ARF), these are also the roles of a physiotherapist. They should also know the evidence that supports the application of MV, and thus develop and implement specific guidelines and ventilation protocols.

Regarding mechanical ventilation, RTs should be experts in every aspect such as; how to choose the specific ventilation mode for each patient, see the curves and analyze the data delivered by it. Thus, RTs should be the experts to

*Address correspondence to this author at the Servicio de Medicina Física y Rehabilitación, Clínica Alemana de Santiago, Avenida Vitacura 5951, Vitacura, Santiago, Chile; Tel: +56222101421; Fax: +56222101421;

E-mail: cromerod@alemana.cl go to when there are doubts about a particular patient. However, independent from the patient's pathology, they should be capable of managing a number of different diseases, besides acute respiratory failure, where by developing specific protocols, flow charts and available evidence the management will be centralized and united. The end result is the appropriate ventilation management of the patients, both invasive and non-invasive curve analysis, pulmonary function and parameters settings, to minimize acute lung injury and optimize ventilatory synchrony of the patient [1].

An important point, as emphasized in the role of the respiratory therapist, described by Kacmarek 2013, is the evaluation of the patient's bed side. The Respiratory Therapist stops being a problem solver and takes the responsibility of evaluating patients. This is why it is critical to know and to be able to recognize the noninvasive mechanical ventilation (NIMV) connection, and failure criteria in a patient with ARF, to act quickly and effectively [1].

In 2004, in Chile, the intensive care unit society, and chiefs of critical hospitals in the metropolitan region developed the "Guidelines for the organization and operation of critical patient units" where the last one was in 1995. These incorporated the physical therapist resource as a professional in the ICU organization, defining it as an indispensable twenty four hour a day position, thus changing the concept of consultant [2]. 
The 2004 guide described the role of the physiotherapist, which has the necessary skills in respiratory areas, neuromuscular care, mechanical ventilation and respiratory therapy. Along with that, recommended the formation and / or postgraduate training in the area of intensive physiotherapy [2]. Appropriate training, techniques and procedures performed by respiratory therapists have been shown to decrease the MV days, ICU resource utilization, and decrease medical and general costs such as the days in an ICU bed [3].

\section{NONINVASIVE MECHANICAL VENTILATION IN ACUTE RESPIRATORY FAILURE}

The management of acute respiratory failure in a critical patient is in a continuous development, both regarding the level of pathophysiological knowledge as clinical outcome and treatment options.

According to technological advances, the development of alternative treatment procedures, which do not use the endotracheal intubation (ETT) or tracheostomy, have placed, since more than a decade ago, noninvasive mechanical ventilation as the first-line of treatment in acute respiratory failure that does not need immediate intubation, and the new standard of care in severe exacerbations of chronic obstructive pulmonary disease (COPD)[4]. The significant reduction in mortality [5] and cost benefit [6] have been associated with; a reduction in ventilator-associated pneumonia (VAP) related to ETT and NIMV, less need for sedation, and faster ventilation disconnection, regarding patients with invasive ventilation.

In 2014 meta-analysis published in Critical Care Medicine [7], seventy eight randomized trials, which support the hypothesis that NIMV improves survival in the acute stage, when used as treatment and prevention of ARF. Furthermore, it suggests that the survival benefit may be lost when the NIMV was belatedly applied as rescue therapy, being less effective than when it is used earlier.

\section{EVIDENCE IN ACUTE RESPIRATORY FAILURE}

The benefits of the use of NIMV in ARF patients have been demonstrated with different degrees of scientific evidence for different groups of patients, so that adequate indication of NIMV depends on the patient's diagnosis and clinical characteristics.

Evidence type 1A supports the use of this technique in patients with acute cardiogenic pulmonary edema, immunosuppression, and chronic obstructive pulmonary disease with hypercapnic exacerbation. In addition, the last group has demonstrated useful to prevent respiratory failure after extubation.

It is difficult to define the role of NIMV in hypoxemic ARF, because the cause ARF may be due to different etiologies, and thus different levels of response can be observed. However, the results depend on the careful selection of patients and monitoring. Above is described in detail the most relevant evidence that supports the use of NIMV in this diagnostics.
In COPD exacerbations, NIMV almost halved mortality, compared with standard therapy [7], also decreasing ETT rate and hospitalization days, being considered as first-line treatment with a strong level of evidence type 1A [8]. COPD patients respond satisfactorily to NIMV, even when the cause of ARF is community-acquired pneumonia, or when it is used as prevention of post-extubation failure. However, this meta-analysis confirmed the survival benefit for patients with COPD with the use of NIMV, provided that it is administered early and timely.

Another diagnosis, where there is strong evidence of type $1 \mathrm{~A}$, is in patients with acute cardiogenic pulmonary edema (ACPE) episodes, who are benefited by adding to the standard medical therapy, a continuous positive airway pressure (CPAP) or Bilevel. The largest ever conducted Randomized Clinical Trial (RCT) on this topic, found no significant survival benefit of NIMV [9]. However, two subsequent meta-analysis $[10,11]$ concluded that NIMV improved survival. Added to that, NIMV besides to avoid complications associated with tracheal intubation, improved lung volumes and respiratory work, it offers other advantages such as reducing heart preload and afterload [12]. Inefficiency in mortality results from the above study [9], was due to patients with no serious complications, and the high crossover rate with NIMV oxygen therapy in the control group. In this meta-analysis there was an improvement in survival, but not significant, and no benefit in ETT rescuing was confirmed, so it suggested that the application of NIMV in early stages of ACPE is not essential.

Regarding to the use of CPAP or Bilevel, there are no differences in mortality related outcomes or when used as an ETT rescue maneuver. Some studies suggest that the Bilevel mode is more comfortable, and provides a faster disappearance of symptoms than CPAP, so it is reasonable to make an attempt to Bilevel, in patients with ACPE, with hypercapnia, or persistence of respiratory distress after a CPAP start [13].

In immunocompromised patients, with solid organ or bone marrow transplantation, who have developed hypoxemic respiratory failure, have shown decreased intubation rates, mortality, and ICU days of stay when treated with NIMV, compared with a conventional treatment $[14,15]$. Patients with acquired immunodeficiency syndrome (AIDS) have reported similar results in a nonrandomized study [16].

The results show that the use of NIMV should be early to prevent acute respiratory failure and progressive complications. The mechanisms responsible for the improvement seem to be: 1) the beneficial effects of PEEP on the redistribution of extravascular fluid, alveolar recruitment and resolution of atelectasis in an early stage; and 2) the capacity of the support pressure to reduce the effort of breathing, and thus help maintain a current volume in order to allow adequate alveolar ventilation.

The use of NIMV in hypoxemic and not hypercapnic ARF remains a complex and controversial issue, because of the heterogeneity of this group of diagnosis. The studies included patients with atelectasis, direct lung injury by 
aspiration or acquired community pneumonia, and indirect lung injury or sepsis after surgery for lung resection.

Pneumonia has been a challenge to noninvasive treatment, and has been identified as a risk factor for the failure of NIMV [14]. Patients in a RCT, who are with a severe acquired community pneumonia, showed that NIMV reduces intubation rates, length of hospital stay and mortality, this occurs only in the subgroup of patients with COPD [17].

Patients with acute lung injury or acute respiratory distress syndrome (ARDS) in the initial phase, whose evolution in the ICU often require prolonged mechanical ventilation, may need pressures that are not well tolerated or cannot be safely provided with NIMV. Studies using NIMV to treat these patients have reported failure rates ranging from $50 \%$ to $80 \%$ [14, 18-20]. However, associated with these patient groups, there were risk factors such as severe hypoxemia, shock and metabolic acidosis [20]. In severe ARDS, a failure rate was reported up to $80 \%$ [21, 22] with a $100 \%$ NIMV failure in shock ARDS patients [23].

\section{CONNECTION CRITERIA}

The success of NIMV depends on various factors, which are detailed below:

I. Appropriate patient selection: based on the best available evidence, considering the potential reversibility, appropriate diagnosis, determine the need for ventilatory support (connection criteria), and the exclusion of patients with contraindications for NIMV [16].

II. Ventilator selection

III. Mask selection

IV. Mode selection

V. Trained team: It is important that the professionals know and evaluate the selection of NIMV, installation and monitoring.

\section{PATIENT SELECTION}

By comparing various RCTs and a systematic review of patients with ARF [14, 16, 24, 25] who received NIMV as first treatment, the following criteria is recognized:

1. Moderate to severe dyspnea.

2. Tachypnea (>24 bpm for hypercapnic ARF, $30 \mathrm{bpm}$ for hypoxemic ARF).

3. Use of accessory respiratory muscles

4. Paradoxical breathing.

5. $\mathrm{PaCO}_{2}>45 \mathrm{mmHg}, \mathrm{pH}<7.35$.

6. $\mathrm{PaFi}<200$.

\section{MASK SELECTION}

NIMV has assumed an important role in the management of selected patients with ARF [16]. It reduces the need for intubation, nosocomial pneumonia and mortality [26, 27]. Good tolerance to the interface has been associated with success of the technique $[28,16]$. Despite the strong evidence supporting its use in ARF, it appears to be underutilized and the failure rate (need for intubation) is high [29].

\subsection{Key Factors for NIMV Interface}

\subsubsection{Discomfort}

Feeling of excessive air pressure, intolerance, skin lesions, leaks and rebreathing; these are the most relevant parameters for the failure related to the interface [30].

\subsubsection{Comfort}

Patient's comfort can be less important than the efficacy of the treatment [28]. The selection of the interface should be according to the anatomy and size of the face. Greater comfort has been associated with better synchrony [29].

\subsubsection{Leak}

The NIMV is based on the principle of leakage compensation. When leakage is excessive, it cannot be properly compensated, resulting in suboptimal ventilatory pressures. Reducing leakage related to the interface and the use of a ventilator with good leakage compensation can reduce asynchrony $[29,30]$. Moreover, it drastically reduces the patient's tolerance and efficacy of NIMV [28].

\subsubsection{Skin Lesions}

Frequent adjustments and care with the position of the mask are needed to prevent skin damage [28]. Frequent monitoring, lubrication, and the change of bearings are required. This may involve the use of more than one type of interface.

\subsubsection{The Dead Space}

The dead space volume of the interface does not influence the exchange of gases, minute ventilation, or breathing effort in the patient. It should not be considered as a limiting factor in the efficacy of NIMV. This condition causes the interfaces to be considered interchangeable, and due to this, you must perform a leakage calibration and adjustment of ventilation parameters if necessary [30,31].

\subsection{Interface Selection}

One of the most important aspects for successful treatment of ARF with NIMV factors is the correct selection of the interface. The development of new materials and standardization in manufacturing has enabled more effective application of NIMV [28, 32]. Most failures are associated with technical problems such as air leakage, discomfort and skin lesions [33]. There is no perfect interface, consider the type of respiratory failure, patient's characteristics and ventilator mode to be used [28, 32]. All interfaces require specific ventilator settings for optimal performance.

\subsubsection{Full Face Masks}

This mask is the most commonly used in the ARF. They provide superior ventilation pressures, less leakage, allow 
breathing through the mouth, and do not require the cooperation of the patient. They can be found in different sizes and shapes. They are associated with less skin lesions. Special care must be taken on the nasal bridge $[28,32,34]$.

\subsubsection{Nasal Masks and Pillows}

There are preferable for ventilation in chronic patients, but are also used in hypercapnic and hypoxemic respiratory failure. The nasal ventilation has limited effectiveness, and in high pressures can produce excessive mouth leaks, which make it difficult to monitor volumes. They have less dead space volume than other interfaces. Produce less claustrophobia, and allow expectoration, facilitates food intake and speech $[28,32]$.

\subsubsection{Helmet}

It is used to avoid skin lesions regardless of the morphology of the face and improve patient comfort [35]. Studies suggest lower efficacy in reducing the pressure of arterial carbon dioxide, and poor patient synchrony because high compressible volume and dead space [36]. Fodil showed that effective dead space is not related to the internal volume of gas $[29,30]$.

\subsubsection{Mouthpieces}

Are the least used due to potential complications such as aspiration syndromes, gastric distension, air leaks through the nose, which require the use of clamps or nose clips [28, 32]. There are standard mouthpieces, which are molded for each patient.

\section{FAILURE CRITERIA}

Furthermore, variables for recognizing NIMV failure depending on the type of ARF are described.

In hypercapnic ARF, if the patient presents some of this criterias, there is a high risk of NIMV failure. Some of the most important failure criteria are: $\mathrm{FR} \geq 35 \mathrm{bpm}, \mathrm{pH}<7.25$, Glasgow Coma Scale (GCS) $\leq 8$.

In hypoxemic ARF, if the patient meets the criteria of ARDS, metabolic acidosis, shock [16, 25, 37]. With regard to $\mathrm{PaFi}$ values, if its previous connection value is $\mathrm{PaFi}<200$ and after the first hour of NIMV connection maintains a PaFi $\leq 146$, it is a good predictor of failure of the technique and therefore, the patient requires intubation [16, 25]. Apart from RCTs, clinical experience, common sense and hospital or clinic resources, are essential to bring a successful life support. Although the guidelines may be helpful, it is important to make a modification according to specific resources and expertise available before implementation.

Despite the large evidence available in the past ten years, more research is needed in many important aspects of NIMV where evidence is weak. Rigorous RCTs are needed to guide the use of NIMV as a method of weaning from IMV, for the prehospital use of NIMV, and its validity as salvage therapy in hypoxemic ARF. Studies to determine the optimal pressures and the best ways to disruption of NIMV are also needed. The more we use NIMV, the more careful we have to be when applying it in the safest way possible. (See Fig. 1)

\section{OTHER CONSIDERATIONS}

\subsection{Sedation and NIMV}

Sedation in patients undergoing NIMV is not well studied, and less protocolized. In a study of Devlin et al. a survey was done and it was found that physiotherapists used sedation in less than $25 \%$ of NIMV patients [38].

We must remember that the success of NIMV is determined by the degree of acceptance and tolerance to it, and one of the main causes for the need of sedation is the poor acceptance of NIMV, which could be determined by the wrong selection of interface and ventilatory mode, where Bilevel modes requires more sedation than spontaneous modes (CPAP) [39, 40].

It is important to take into consideration when administering sedation to a patient with ARF, to evaluate complications such as respiratory center depression, hypoventilation, tongue upper airway obstruction, the decreased of cough reflex, the efficiency in the removal of secretions, risk of aspiration by vomiting, hypotension, among others [39, 41]. In 2013, Scala described the sedation goal as "conscious sedation", where the patient is awake or wakes up easily, with attenuation of discomfort induced by the NIMV, without the complications listed above [39].

As the evidence of sedation is not strong, and NIMV failure includes discomfort, anxiety, agitation and patientventilator asynchrony, we must also consider that sedation may be disadvantageous to hide NIMV failure due to progression of the underlying disease and may delay intubation in these patients. Among the most common drugs used to adapt patients to NIMV are Midazolam, which is used in $33 \%$ of the cases, and opioids, in $29 \%$. Dexmedetomidine, Ketamine and propofol are also used [38]. Dexmedetomidine seems to be a drug with improved characteristics in relation to the above points, it has no direct effect on the permeability of the upper airways, and when used as adjunct therapy, it can reduce opioid requirements. Additionally it produces less depression in the respiratory center [40].

Opioids and benzodiazepines decrease the diameter of the upper airway and can probably cause damage during NIMV. Propofol has also been shown to increase the probability of collapse of the upper airway [40]. Ketamine does not cause respiratory depression in doses for analgesia, it can decrease airway resistance, improve dynamic compliance, retain the functional residual capacity, minute volume, tidal volume, and retain pharyngeal and laryngeal protective reflexes. But it can cause salivation and effects on the sympathetic nervous system, so it is not recommended in patients with decompensated heart failure (ACPE) [40].

\subsection{Perspectives from Chile}

To learn about the Chilean reality, we conducted a survey via email, during the months of January and February in 2015 , in the ICU of several centers. The survey was answered by 47 physiotherapists, of which, $53 \%$ work in the public sector, $26 \%$ in the private sector and $21 \%$ in both. Out of this survey, $88 \%$ of physiotherapists are in charge of the NIMV assembling, and $85 \%$ together with this group also 


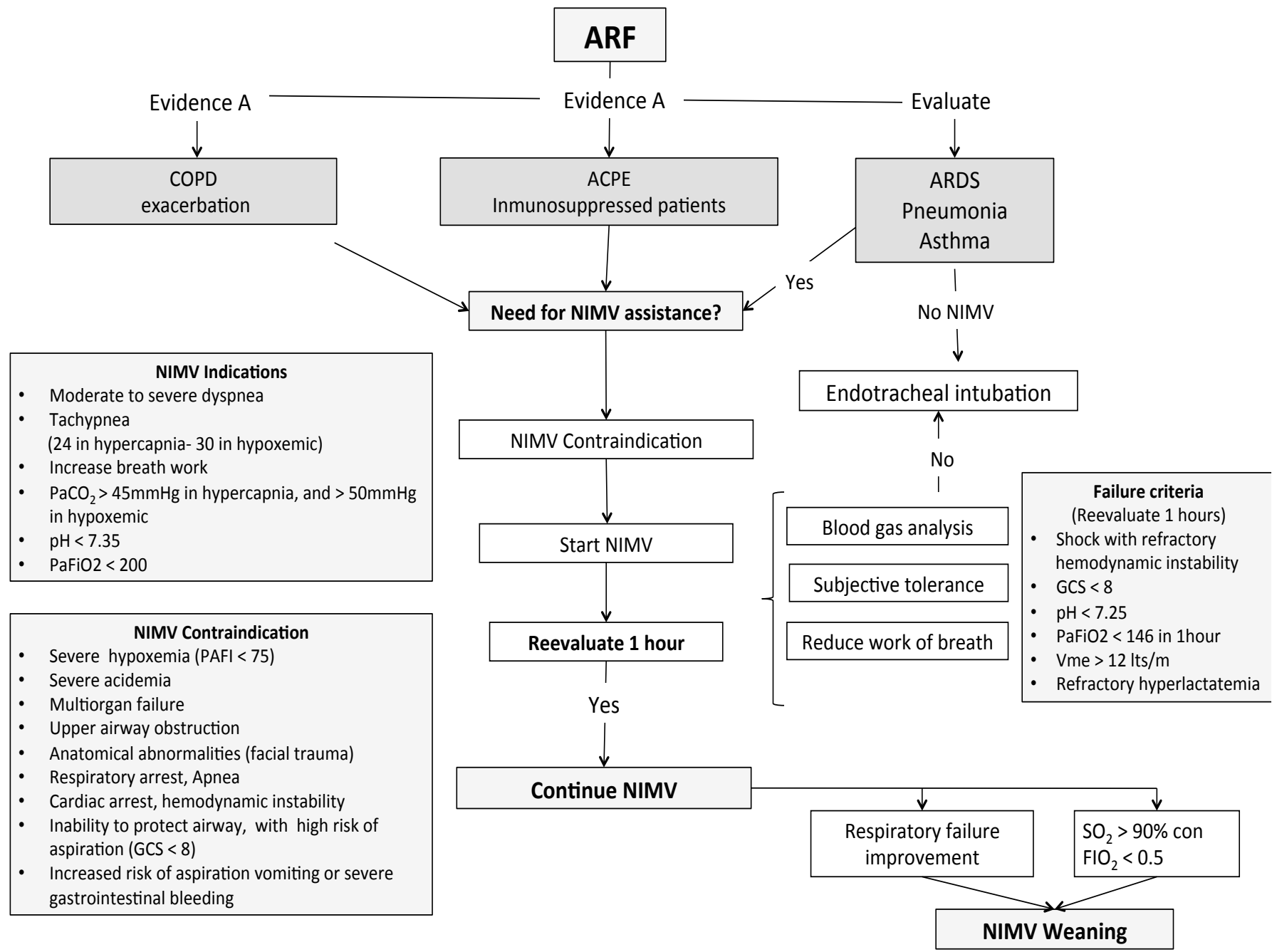

Fig. (1). Management of acute respiratory failure with noninvasive mechanical ventilation (NIMV). Flow chart developed by ICU physiotherapist team, from Clínica Alemana de Santiago, Santiago, Chile. ARF= Acute respiratory failure, NIMV= Noninvasive mechanical ventilation, $\mathrm{COPD}=$ Chronic obstructive pulmonary disease, $\mathrm{ACPE}=$ Acute cardiogenic pulmonary edema, $\mathrm{ARDS}=\mathrm{Acute}$ respiratory distress syndrome, $\mathrm{PAFI}=\mathrm{PaO}_{2} / \mathrm{FiO}_{2}, \mathrm{GCS}=$ Glasgow coma scale, $\mathrm{Vme}=$ Expiratory minute volume, $\mathrm{SO}_{2}=$ Oxygen saturation .

perform the bedside programming, and only $9 \%$ said that programming is in charge of the medical unit.

As previously stated, the diseases that have better evidence of NIMV use and are frequently used by; COPD (87\%), followed by the ACPE (43\%) and finally in immunosuppressed patients (13\%). The most frequent ventilatory mode used by physiotherapists, is the $\mathrm{S} / \mathrm{T}$ or Bilevel mode (88\%), besides the condition being treated.

During the NIMV criteria connection, they constantly evaluate their patients, we found that the most important aspect to them at the moment of deciding the need for the NIMV connection are; the arterial blood gas (49\%), patient ventilatory mechanics $(28 \%)$, accessory muscles use $(13 \%)$, and dyspnea (10\%). And among the least important criteria to decide the need for NIMV, are radiological examinations $(55 \%)$, and $\mathrm{O}_{2}$ saturation (35\%).

\section{CONCLUSION}

Is the job of physiotherapists the bedside evaluation for NIMV. Most of them have a clear criterion according to the literature. They work together with the medical units, and they are the professionals in charge of following, monitoring and adapting the patients to the NIMV.

Sometimes the ventilator mode is not the main factor when adapting and adjusting the NIMV, because there are others factors, such as interfaces, the leakage and the diagnosis of the patients that guide the physiotherapist to make decisions about changing the ventilator mode or suppressed the ventilation. The best ventilatory mode to use with patients should be the best handled, based on the evidence, the clinical experience and the type of ventilator and its use by the physiotherapist. 
Physiotherapists in Chile are trained professionals who are in charge of the use of NIMV in the ICU. The evidence supports that, and with the role of respiratory therapist in most of the studies, the Chilean perspective does not differ when compared with studies shown above.

\section{CONFLICT OF INTEREST}

The authors confirm that this article content has no conflict of interest.

\section{ACKNOWLEDGEMENTS}

All authors helped write the manuscript and have seen and approved the final version.

Special thanks to Jerónimo Graf and ICU of Clinica Alemana de Santiago.

\section{REFERENCES}

[1] Kacmarek R. Mechanical ventilation competencies of the respiratory therapist in 2015 and beyond. Respir Care 2013; 58: 1087-96.

[2] Sáez E, Infante A. Guías 2004 de organización y funcionamiento de unidades de pacientes críticos. Revista Chilena de Med Intens 2004; 19: 209-23.

[3] Li J, Zhan Q, Liang Z, et al. Respiratory care practices and requirements for respiratory therapists in Beijing intensive care units. Respir care 2012; 57: 370-6.

[4] Brochard I. Noninvasive ventilation for acute exacerbations of COPD a new standard of care. Thorax 2000; 55: 817-8.

[5] Girou E, Brun-Buisson C, Taillé S, Lemaire F, Brochard L. Secular trends in nosocomial infections and mortality associated with noninvasive ventilation in patients with exacerbation of COPD and pulmonary edema. JAMA 2003; 290: 2985-91.

[6] Keenan SP; Gregor J, Sibbald WJ, Cook D, Gafni A. Noninvasive positive pressure ventilation in the setting of severe, acute exacerbations of chronic obstructive pulmonary disease: more effective and less expensive. Crit Care Med 2000; 28: 2094-102.

[7] Cabrini L, Landoni G, Oriani A, Plumari V, et al. Noninvasive ventilation and survival in acute care settings: a comprehensive systematic review and meta-analysis of randomized controlled trials. Crit Care Med 2015; 43: 880-8.

[8] Hill N, Brenann J, Garpestad E, Nava S. Noninvasive ventilation in acute respiratory failure. Crit Care Med 2007; 35: 2402-7.

[9] Gray A, Goodacre S, Newby DE, et al. 3CPO trialists: Noninvasive ventilation in acute cardiogenic pulmonary edema. N Engl J Med 2008; 359: $142-51$

[10] Potts JM. Noninvasive positive pressure ventilation: Effect on mortality in acute pragmatic meta- analysis. Pol Arch Med Wewn 2009; 119: 349-53.

[11] Weng CL, Zhao YT, Liu QH, et al. Meta-analysis: No invasive ventilation in acute cardiogenic pulmonary edema. Ann Intern Med 2010; 152: 590-600.

[12] Mehta S, Al-Hashim AH, Keenan SP. Noninvasive Ventilation in patients with acute cardiogenic pulmonary edema. Respir Care 2009; 54:186-95.

[13] Liesching T, Nelson DL, Cormier K, et al. Randomized trial of Bilevel noninvasive ventilation $v s$ continuous positive pressure to treat acute pulmonary edema. J Emerg Med 2014; 46: 130-40.

[14] Antonelli M, Conti G, Bufi M, et al. Noninvasive ventilation for treatment of acute respiratory failure in patients undergoing solid organ transplantation: a randomized trial. JAMA 2000; 283: 235-41.
[15] Hilbert G, Gruson D, Vargas F, et al. Noninvasive ventilation in imm unosuppressed patients with pulmonary infiltrates and acute respiratory failure. N Engl J Med 2001; 344: 481-7.

[16] Boldrini R, Fasano L, Nava S. Noninvasive mechanical ventilation. Curr Opin Crit Care 2012; 18: 48-53.

[17] Confalonieri M, Potena A, Carbone G, Porta RD, Tolley EA, Umberto Meduri G. Acute respiratory failure in patients with severe communityacquired pneumonia. A prospective randomized evaluation of noninvasive ventilation. Am J Respir Crit Care Med 1999; 160: 158591.

[18] Ferrer M, Esquinas A, Leon M, Gonáalez G, Alarcón A, Torres A. Noninvasive ventilation in severe hypoxemic respiratory failure. A randomized clinical trial. Am J Respir Crit Care Med 2003; 168: 143844.

[19] Rocker GM, Mackensie MG, Williams B, Logan PM. Noninvasive positive pressure ventilation. successful outcome in patients with acute lung injury/ARDS. Chest 1999; 115: 173-7.

[20] Rana S, Hussam J, Gay P, et al. Failure of non-invasive ventilation in patients with acute lung injury: observational cohort study. Crit Care 2006; 10: R79.

[21] Nava S, Hill N. Non-invasive ventilation in acute respiratory failure. Lancet 2009; 374: 250-9.

[22] Agarwal R, Aggarwal AN, Gupta D. Role of noninvasive ventilation in acute lung injury/acute respiratory distress syndrome: a proportion meta-analysis. Respir Care 2010; 55: 1653-60.

[23] Hess DR. Noninvasive ventilation for acute respiratory failure. Respir Care 2013; 58: 950-72.

[24] Keenan SP, Sinuff T, Cook DJ, Hill NS. Does noninvasive positive pressure ventilation improve outcome in acute hypoxemic respiratory failure? a systematic review. Crit Care Med 2004; 32: 2516-23.

[25] Hess D, Fessler HE. Should noninvasive positive-pressure ventilation be used in all forms of acute respiratory failure? Resp Care 2007; 52: 568-81

[26] Evans TW. International Consensus Conferences in Intensive Care Medicine: non- invasive positive pressure ventilation in acute respiratory failure. Organised jointly by the American Thoracic Society, the European Respiratory Society, the European Society of Intensive Care Medicine, and the Société de Réanimation de Langue Française, and approved by the ATS Board of Directors, December 2000. Intensive Care Med 2001; 27: 166-78.

[27] Hess D. The evidence for noninvasive positive-pressure ventilation in the care of patients in acute respiratory failure: a systematic review of the literature. Respir Care 2004; 49: 810-29.

[28] Nava S, Navalesi P, Gregoretti C. Interfaces and humidification for noninvasive mechanical ventilation. Respir Care 2009; 54: 71-84

[29] Hess D. Patient-ventilator interaction during non-invasive ventilation. Respir Care 2011; 56: 153-65.

[30] Fodil R, Lellouche F, Mancebo J, et al. Comparison of patientventilator interfaces based on their computerized effective dead space. Intensive Care Med 2011; 37: 257-62.

[31] Fraticelli AT, Lellouche F, L'her E, Taillé S, Mancebo J, Brochard L. Physiological effects of different interfaces during non-invasive ventilation for acute respiratory failure. Crit Care Med 2009; 37: 93945.

[32] Elliot MW. The interface: crucial for successful noninvasive ventilation Eur Respir J 2004; 23: 7-8.

[33] Gregoretti C, Confalonieri M, Navalesi P, et al. Evaluation of patien skin breakdown and comfort with a new face mask for non-invasive ventilation: a multi-center study. Intensive Care Med 2002; 28: 278-84.

[34] Roy B, Cordova F, Travaline J, D’Alonzo G, DO J, Criner G. Full face mask for non-invasive positive-pressure ventilation in patients with acute respiratory failure. J Am Osteopath Assoc 2007; 107: 148-56.

[35] Pisani L, Mega C, Vaschetto R, et al. Oronasal mask versus helmet in acute hypercapnic respiratory failure. Eur Respir J 2015; 45: 691-9.

[36] Navalesi P, Costa R, Ceriana $\mathrm{P}$, et al. Non-invasive ventilation in chronic obstructive pulmonary disease patients helmet versus facial mask. Intensive Care Med 2007; 33: 74-81.

[37] Antonelli M, Conti G, Moro ML, et al. Predictors of failures of noninvasive positive pressure ventilation in patients with acute hypoxemic respiratory failure:A multicenter study. Intensive Care Med 2001; $27: 1718-28$ 
[38] Devlin J, Nava S, Fong J, Bahhady I, Hill NS. Survey of sedation practices during noninvasive positive-pressure ventilation to treat acute respiratory failure. Crit Care Med 2007; 35: 298-302.

[39] Scala R. Sedation during non-invasive ventilation to treat acute respiratory failure. Shortness Breath 2013; 2: 35-43.
[40] Longrois D, Conti G, Mantz J, Falthauser A, Aantaa R, Tonner P. Sedation in non-invasive ventilation: do we know what to do (and why)?. Multidiscip Resp Med 2014, 9: 6.

[41] Gay P. Complications of noninvasive ventilation in acute care. Respir Care 2009; 54: 246-57.

Received: March 14, 2015

Revised: April 16, 2015

Accepted: April 16, 2015

(C) Hidalgo et al.; Licensee Bentham Open.

This is an open access article licensed under the terms of the Creative Commons Attribution Non-Commercial License (http://creativecommons.org/licenses/by-nc/3.0/) which permits unrestricted, non-commercial use, distribution and reproduction in any medium, provided the work is properly cited. 